\title{
Recurrent Mastitis and Its Management in a Secondary Care Hospital: A Case Report
}

\author{
Indu Tharayappurath Haridas, Subitha Babu, Roopa Satyanarayan Basutkar, Sivasankaran \\ Ponnusankar
}

Department of Pharmacy Practice, JSS College of Pharmacy, Udhagamandalam- 643 001, JSS University, Mysore, INDIA.

\begin{abstract}
Introduction: Mastitis is a painful inflammation of the breast, commonly seen during the lactating period. Case: We present a case of recurrent mastitis of a patient who visited for treatment to a secondary care hospital, Udhagamandalam and describes the treatment strategies followed. The treatment given was found to be in accordance with the world health organization guidelines for treatment of mastitis, Academy of Breast feeding medicine protocol committee, Australia and National treatment guidelines for antimicrobial use in infectious disease (version 1.0, 2016) by the Government of INDIA. The recurrence of mastitis observed in this patient emphasizes the need of educating lactating mothers effectively regarding regular feeding and proper breast feeding techniques, which may enabling them to identify and resolve the predisposing factors of possible breast feeding disorders.
\end{abstract}

Key words: Mastitis, Recurrence, Management, Secondary Care, Guidelines.

\section{INTRODUCTION}

Mastitis is defined as a painful inflammation of the breast with or without bacterial infection, observed during the lactating period. ${ }^{1}$ Nearly, $20-25 \%$ of lactating women during their lactating period suffer from mastitis globally and in INDIA, the incidence of breast abscess ranges from 0.4 to $11 \%$ in lactating mothers. ${ }^{2}$ The unilateral breast mass and flu-like manifestations such as malaise, fever, dizziness and cold are the classical manifestations of mastitis. ${ }^{3}$ The poor drainage of milk due to inadequate breast feeding may lead to block formation in the milk ducts. This may further cause inflammation with pain and swelling. Similarly, the cracking of nipples observed during mastitis may promote the entry of microorganism such as Staphylococcus aureus, Escherichia coli and Hemophilus influenza causing infection. ${ }^{4,5} \mathrm{~A}$ case of recurrent mastitis in a lactating mother is described here.

\section{CASE REPORT}

A 26-year-old woman (Gravida ${ }_{2}$, Parity ${ }_{2}$,
Abortion $_{0}$ ) of two months of post-delivery was presented to the in-patient department of obstetrics and gynecology unit of secondary care public hospital, Udhagamandalam, The Nilgiris on $16^{\text {th }}$ September 2015, with complaints of fever, pain, warmth and redness on the right breast since three days. The patient was employed and had a history of taking oral contraceptives. She suffered from mild mastitis during the lactation period of her first delivery, which was managed with Tablet Paracetamol (500 mg, thrice daily) and adequate supportive care.

The involution status was assessed based on uterine fundal height and lochial consistency and amount. The vitals of the patient were as follows; blood pressure: 100/60 mmHg, pulse rate: 78 beats/min, respiratory rate: 16 breaths/min and temperature $101^{\circ} \mathrm{F}$. The altered white blood cell count and presence of pus cells showed the presence of infection (Table 1). The biopsy and mammogram tests were not performed and HIV test was found to be non-reactive. The patient was diagnosed with recurrent mastitis of infectious nature.
DOI: 10.5530ijopp.10.1.13

Address for correspondence: Dr. S. Ponnusankar, Professor \& Head Department of Pharmacy Practice JSS College of Pharmacy, Rocklands, Post Box No. 20, Ooty-643001, the Nilgiris, TamilNadu, INDIA.

Jagadguru Sri Shivarathreeshwara University, Mysuru, INDIA. Phone no: +: 0423-2443393, 2443847, H/P: +91-9489613428 E-mail: ponnusankarsivas@ gmail.com 
On day 1 , she was administered with parenteral antibiotics such as Cefotaxime (1 gm) and Gentamicin $(80 \mathrm{mg}) 12$ hourly along with Tablet Acetaminophen $(500 \mathrm{mg}$, thrice daily). The tenderness and warmth was sustained on the right breast on day 2 as well, thus indicating the need for adding additional drugs to the existing prescription of day 1 and the same was continued for the next six days. The medications prescribed were, a combination of Piperacillin and Tazobactum (4.5 mg, Intravenous (IV) bolus, bd), Tablet Metronidazole (400 mg, tid), Tablet Ibuprofen (200 mg, bd), Tablet Ranitidine (150 mg, bd), Tablet Ferrous sulphate ( $333 \mathrm{mg}$, od), Tablet Vitamin B complex (vitamin B1-2 mg, vitamin B2-2 mg, niacinamide - $25 \mathrm{mg}$, and calcium - $1 \mathrm{mg}$ ) od, Tablet Calcium (150 mg, od) and IV infusion of ringer lactate $(500 \mathrm{ml})$ at the rate of $100 \mathrm{ml} / \mathrm{h}$. Hot fermentation was also recommended.

On day 8 , the abscess due to pus accumulation on the right breast was confirmed by ultrasonography. A surgical incision and drainage was performed to remove the pus. After surgery, the same antibiotics along with Tablet Diclofenac (50 mg, bd) and Capsule Omeprazole (25 $\mathrm{mg}$, bd) were given to the patient and continued for four days with hot fermentation and tight dressing for effective milk removal.

Patient was doing better and was trained on self- dressing of the incision area, proper positioning of baby and warm compressions. She was re-emphasized about the need of feeding the baby regularly and counseled to take sufficient fluid, to wash hands before feeding after a nappy change, to wear loose comfortable clothing and to take enough rest. She was discharged on the $12^{\text {th }}$ day with the prescription of oral medications such as Omeprazole (25 mg, bd), Diclofenac (50 mg, bd, sos) and Vitamin B complex for 15 days.

\section{DISCUSSION}

The age of the patient and the history of use of oral contraceptives were identified as predisposing factors of mastitis in this patient. The hormonal changes associated with the use of oral contraceptives may cause accumulation of debris and dead skin cells in the milk ducts and may lead to the occurrence of bacterial infections, 21-35 years is the common age for mastitis. ${ }^{4-6,7}$ Patient admitted that, she often had long gaps between feeds and missed feeding because of her job schedule. This might have caused milk stasis and milk accumulation, promoted the growth of microorganism, which later developed to infectious mastitis.

The symptomatic management, effective milk removal,

\begin{tabular}{ccc}
\hline \multicolumn{3}{c}{ Table 1: Laboratory investigation report. } \\
$\begin{array}{c}\text { Clinical } \\
\text { Parameters }\end{array}$ & Result obtained & Normal range \\
Hemoglobin & $13.8 \mathrm{~g} / \mathrm{dL}$ & $12-16 \mathrm{~g} / \mathrm{dL}$ \\
Bleeding time & $2^{\prime} 00^{\prime \prime} \mathrm{min}$ & $<5 \mathrm{~min}$ \\
Clotting time & $4^{\prime} 00^{\prime \prime} \mathrm{min}$ & $5-9 \mathrm{~min}$ \\
Differential count & & \\
(DC) & $71 \%$ & $54-62 \%$ \\
Polymorphs & $19 \%$ & $25-33 \%$ \\
Lymphocytes & $10 \%$ & $3-7 \%$ \\
Monocytes & & \\
Urine Analysis & & $\mathrm{Nil}$ \\
Urine albumin & ++ & $1 / 2 / \mathrm{hpf}$ \\
Pus cells & $1-2 \mathrm{pc} / \mathrm{hpf}$ & $1 / 2 / \mathrm{hpf}$ \\
Epithelial pus cells & $4-5 \mathrm{epc} / \mathrm{hpf}$ &
\end{tabular}

antibiotics and effective counseling was recommended for the treatment for mastitis by WHO. ${ }^{8}$ As the patient had the symptoms such as pain and fever, analgesics such as Acetaminophen, Ibuprofen and Diclofenac were prescribed. The anti-inflammatory analgesic Ibuprofen (maximum dose up to $1.6 \mathrm{~g} /$ day) and Acetaminophen were found to be compatible during lactating period. ${ }^{8,9}$ The patient was exposed with four different parenteral antibiotics to cover the spectrum of microbes which causes mastitis, as there was limited facilities available in the hospital to perform culture and sensitivity investigations. However, the prescription of antibiotics such as Cefotaxime (safe up to $2 \mathrm{~g} /$ day), Gentamicin (safe up to $7 \mathrm{mg} / \mathrm{kg} /$ day), Piperacillin- Tazobactum combination $(4.5 \mathrm{mg}$, bd) and Metronidazole $(500 \mathrm{mg}$, tid) for treating mastitis were found to be in accordance with National treatment guidelines for antimicrobial use in infectious disease (version 1.0) by Government of INDIA. ${ }^{10}$ As the poor nutritional status is one of the predisposing factors for mastitis, patient was provided with Vitamin and Ferrous sulphate tablets to maintain a good nutritional status. ${ }^{11}$ Similarly, hot fermentation was suggested to stimulate the oxytocin reflex and milk producton. $^{12}$

In this case, ultrasound was not performed to recognize large breast abscess until the day 8 to confirm breast abscess. When it recognized, the abscess was found to be very large and immediately surgical drainage was performed instead of needle aspiration, which was in accordance with the Academy of Breast feeding Medicine clinical protocol, Australia, which suggests that, breast feeding should be continued even after surgery in such a way that the mouth of baby does not touch the drain. ${ }^{13}$ The discontinuation of breast feeding and improper infant nutrition is a common trend observed among the lactating women with mastitis due to the misconception of spreading infection. ${ }^{1}$ The uncorrected and poor 
breastfeeding techniques might be the reason for recurrence of mastitis in this case..$^{7-12-14}$ Thus, the patient was reemphasized to improve milk feeding frequency and provided with emotional support and reassurance.

\section{CONCLUSION}

The long gaps, missed feeding, and uncorrected or poor breastfeeding techniques led to recurrence of mastitis in this patient. The treatment pattern followed was found to be in accordance with WHO treatment guidelines for mastitis, ABM protocol committee, Australia and National treatment guidelines for antimicrobial use in infectious disease (version 1.0, 2016) by Government of INDIA. The patient was counseled about supportive measurement and re-emphasized regarding frequent breast feeding. The recurrence of mastitis observed in this patient emphasized that it is essential to conduct counseling programs for pregnant and lactating women to identify and resolve the predisposing factors of mastitis which in turn decrease the incidence of breastfeeding disorders.

\section{ACKNOWLEDGMENT}

The authors acknowledge the support provided by the Government Headquarters Hospital, Udhagamandalam.

\section{CONFLICTS OF INTEREST}

There are no conflicts of interest.

\section{ABBREVIATIONS USED}

IV: Intravenous; BD: twice daily; TID: thrice daily; OD: once daily; WHO: World Health organization; ABM: Academy of breastfeeding medicine.

\section{REFERENCES}

1. Spencer JP. Management of mastitis in breastfeeding women. Am Fam Physician. 2008;78(6):727-31. PMid:18819238.

2. Scott JA, Robertson M, Fitzpatrick J, Knight C, Mulholland S. Occurrence of lactational mastitis and medical management: a prospective cohort study in Glasgow. International Breastfeeding Journal. 2008;3(1):21. https://doi. org/10.1186/1746-4358-3-21; PMid:18721487 PMCid:PMC2542350.

3. Al-Khaffaf B, Knox F, Bundred NJ. Idiopathic granulomatous mastitis: a 25-year experience. Journal of the American College of Surgeons. 2008;206(2):269-73. https://doi.org/10.1016/j.jamcollsurg.2007.07.041; PMid:18222379.

4. Kaufmann R, Foxman B. Mastitis among lactating women: occurrence and risk factors. Social science \& medicine. 1991;33(6):701-5. https://doi. org/10.1016/0277-9536(91)90024-7.

5. Delgado S, Arroyo R, Martín R, Rodríguez JM. PCR-DGGE assessment of the bacterial diversity of breast milk in women with lactational infectious mastitis. BMC infectious diseases. 2008;8(1):51. https://doi.org/10.1186/1471-2334-851; PMid:18423017 PMCid:PMC2383900

6. Jonsson S, Pulkkinen MO. Mastitis today: incidence, prevention and treatment. InAnnales chirurgiae et gynaecologiae. Supplementum 1993 Dec (Vol. 208, pp. 84-87).

7. Fetherston C. Risk factors for lactation mastitis. Journal of Human Lactation. 1998;14(2):101-9. https://doi.org/10.1177/089033449801400209; PMid:9775842.

8. Mastitis: causes and management. Geneva: World Health Organization (WHO); 2000.

9. Flint J, Panchal S, Hurrell A, van de Venne M, Gayed M, Schreiber K et al. BSR and BHPR guideline on prescribing drugs in pregnancy and breastfeeding-Part II: analgesics and other drugs used in rheumatology practice. Rheumatology (Oxford), 2016: (Epub ahead of print). https://doi.org/10.1093/rheumatology/ kev405; https://doi.org/10.1093/rheumatology/kev404; PMid:26750124.

10. National treatment guidelines for antimicrobial use in infectious disease (version 1.0), national center for disease control, directorate general of health services, Ministry of Health and family welfare, Government of INDIA; 2016.

11. Miranda R, Saravia NG, Ackerman R et al. Effect of maternal nutritional status on immunological substances in human colostrum and milk. The American journal of clinical nutrition. 1983;37(4):632-40.PMid:6837495.

12. Amir LH. ABM clinical protocol\# 4: Mastitis, revised March 2014. Breastfeeding Medicine. 2014;9(5):239-43. https://doi.org/10.1089/bfm.2014.9984; PMid:24911394 PMCid:PMC4048576.

13. Kessler E, Wolloch Y. Granulomatous mastitis: a lesion clinically simulating carcinoma. American journal of clinical pathology. 1972, ;58(6):642-6. https:// doi.org/10.1093/ajcp/58.6.642; PMid:4674439.

14. Inch S, Fisher C. Mastitis: infection or inflammation?. The Practitioner. 1995;239(1553):472-6. 